\title{
BMJ
}

\section{Transdermal and oral hormone replacement therapy and the risk of stroke: a nested case-control study}

\author{
Christel Renoux, fellow, ${ }^{1}$ Sophie Dell'Aniello, statistician, ${ }^{1}$ Edeltraut Garbe, professor, ${ }^{2}$ Samy Suissa, \\ professor $^{1}$
}

${ }^{1}$ McGill Pharmacoepidemiology Research Unit, Center for clinical epidemiology, Jewish General Hospital, and the Departments of Epidemiology and Biostatistics and of Medicine, McGill University, Montreal, Canada H3T 1E2

${ }^{2}$ Department of Clinica Epidemiology, Bremen Institute for Prevention Research and Social Medicine, University of Bremen, 28359 Bremen,

Germany

Correspondence to: S Suissa samy.suissa@mcgill.ca

Cite this as: $B M / 2010 ; 340: c 2519$ doi:10.1136/bmj.c2519

\section{ABSTRACT}

Objectives To determine the risk of stroke associated with oral and transdermal routes of administration of hormone replacement therapy.

Design Population based nested case-control study. Setting About 400 general practices in the United Kingdom contributing to the General Practice Research Database.

Participants Cohort of all women in the database aged 50-79 years between 1 January 1987 and 31 October 2006 who were members of a practice that fulfilled predefined quality criteria and without a diagnosis of stroke before cohort entry. For each case of stroke occurring during follow-up, up to four controls were selected from among the cohort members in the risk sets defined by the case. Exposure to hormone replacement therapy (HRT) was categorised into oestrogens only, oestrogens plus progestogen, progestogen only, and tibolone. Oestrogens were further subdivided according to the route of administration (oral $v$ transdermal) and dose (high $v$ low).

Main outcome measures Rate ratio of stroke associated with current use of oral and transdermal HRT compared with no use. Current use was considered as a prescription whose duration included the index date.

Results There were 15710 cases of stroke matched to 59958 controls. The rate of stroke in the cohort was 2.85 per 1000 per year. The adjusted rate ratio of stroke associated with current use of transdermal HRT was 0.95 $(95 \% \mathrm{Cl} 0.75$ to 1.20$)$ relative to no use. The risk of stroke was not increased with use of low oestrogen dose patches (rate ratio 0.81 (0.62 to 1.05)) compared with no use, whereas the risk was increased with high dose patches (rate ratio 1.89 (1.15 to 3.11)). Current users of oral HRT had a higher rate of stroke than non-users (rate ratio 1.28 (1.15 to 1.42)) with both low dose and high dose.

Conclusions The use of transdermal HRT containing low doses of oestrogen does not seem to increase the risk of stroke. The presence of residual confounding, however, cannot be entirely excluded in the interpretation of this finding.

\section{INTRODUCTION}

Hormone replacement therapy (HRT), especially oestrogen alone or in combination with progestogen, is used for the relief of climacteric symptoms in postmenopausal women. Although many observational studies have suggested a protective effect against cardiovascular disease, this has been challenged by the results of randomised controlled trials. In particular, several clinical trials have shown an increased risk of stroke associated with HRT in postmenopausal women. This was confirmed in recent meta-analyses showing a 30\% increased risk of stroke, identical for oestrogens alone or in combination with progestogen. ${ }^{1-3}$ However, these clinical trials evaluated oral HRT and did not explore other routes of administration. One observational study suggested a lower risk of transient ischaemic attack with transdermal oestrogen use compared with oral oestrogen, but the risk of stroke could not be estimated because of the small number of cases. ${ }^{4}$

Transdermal oestrogen preparations are effective in the treatment of postmenopausal symptoms ${ }^{5}$ in a manner similar to oral oestrogens. ${ }^{6}$ Several studies suggest that the transdermal route exerts a different impact on biological cardiovascular risk markers by avoidance of the first pass effect in the liver. ${ }^{7}$ Thus different routes of administration of HRT may be associated with a different risk of cerebrovascular events in postmenopausal women.

The objective of our study was to assess the risk of stroke associated with oral and transdermal routes of administration of HRT in a cohort of postmenopausal women using a nested case-control analysis.

\section{METHODS}

Source of data

We used the United Kingdom's General Practice Research Database (GPRD), for which detailed characteristics have been described elsewhere. ${ }^{89}$ In brief, the GPRD is a large computerised database of anonymised longitudinal records containing medical information on a population of more than six million patients (about $8 \%$ of the UK population) who participate in this database via about 400 contributing general practices. The population in the database broadly reflects the demographics of the general UK population. Information collected includes demographic characteristics, lifestyle factors, medical symptoms 
and diagnoses, laboratory tests and test results, prescriptions with dose instructions, referrals to specialists, and hospital discharge reports. Quality control of data entry and consistency with medicals files are checked regularly, and several studies have shown the high quality of recorded data. ${ }^{1011}$

\section{Study design}

The cohort and case-control subjects used in this study have been reported previously. ${ }^{12}$ Briefly, we conducted a case-control study within the cohort consisting of all women in the GPRD aged 50-79 between 1 January 1987 and 31 October 2006 who were members of a practice that fulfilled predefined quality criteria ("up to standard"). For all cohort members, cohort entry (time zero) was defined by the latest of the following: 1 January 1987, the patient's 50th birthday, or the date of joining the "up to standard" practice. In other words, all women aged 50-79 on 1 January 1987 and registered with a suitable practice entered the study at this date. Younger women or women not followed in an "up to standard" practice entered the study later, at the time they fulfilled both entry criteria of age and registration with a practice up to standard. Women with a diagnosis of stroke before joining a suitable practice or their 50th birthday were excluded. All cohort subjects were followed until the date of stroke, death, end of registration with the practice, or end of the study period (31 October 2006), whichever occurred first.

\section{Cases and controls}

Within the study cohort, we identified all cases of a first recorded diagnosis of stroke (ischaemic, haemorrhagic, or not further specified) occurring during the study period by means of OXMIS or Read diagnostic codes referring to these events. The same diagnostic codes related to stroke were used in a previous study of the association between cyclo-oxygenase- 2 selective non-steroidal anti-inflammatory drugs and stroke. ${ }^{13}$ The index date was defined as the date of the first recorded stroke.

Each risk set, at each case's index date, included all individuals who were still at risk of the event (controls). For each case, up to four controls were randomly selected among the cohort members in the risk sets defined by the case. Controls were matched to cases on age (within 1 year) at the date of the case's diagnosis, the general practice attended, and the year of start in the practice. The index date for the controls was defined as the event date for their matched case. Matching on calendar time allowed us to control for trends over time in the use of HRT.

\section{Exposure information}

We identified all prescriptions for any HRT issued during the year preceding the index date - that is, in the year before the date of stroke for cases and in the year before the same index date for matched controls. HRT products were categorised as oestrogens only, oestrogens plus progestogen, progestogen only, and tibolone. Oestrogens were further subdivided according to the route of administration (oral or transdermal) and to the dose. Hence, oral low dose products contained $\leq 0.625 \mathrm{mg}$ of equine oestrogen or $\leq 2 \mathrm{mg}$ of estradiol and high dose products contained $>0.625 \mathrm{mg}$ of equine oestrogen or $>2 \mathrm{mg}$ of estradiol; transdermal low dose products contained $\leq 50 \mu \mathrm{g}$ of oestrogen and high dose products contained $>50 \mu \mathrm{g}$. The duration of each prescription was calculated from the number of tablets or patches prescribed, combined with dosing instructions. When no dosage instructions were provided with the prescription, we imputed the mean duration of use of the same HRT product.

\section{Data analysis}

Incidence rate ratios of stroke associated with current use of the various HRT products and the route of administration were estimated from the odds ratios calculated by means of conditional logistic regression. Current use was considered as a prescription whose duration included the index date. Current HRT users were categorised into the following groups: oral oestrogens, transdermal oestrogens, oral oestrogens plus progestogen, transdermal oestrogen plus progestogen, tibolone, progestogen only, and more than one type of HRT. Past use was defined by a prescription of HRT in the year before the index date that stopped before the index date. Past users were grouped together irrespective of the type and route of HRT used. Non-users were individuals with no prescription of any HRT in the year before the index date and constituted the reference group. In addition, we estimated

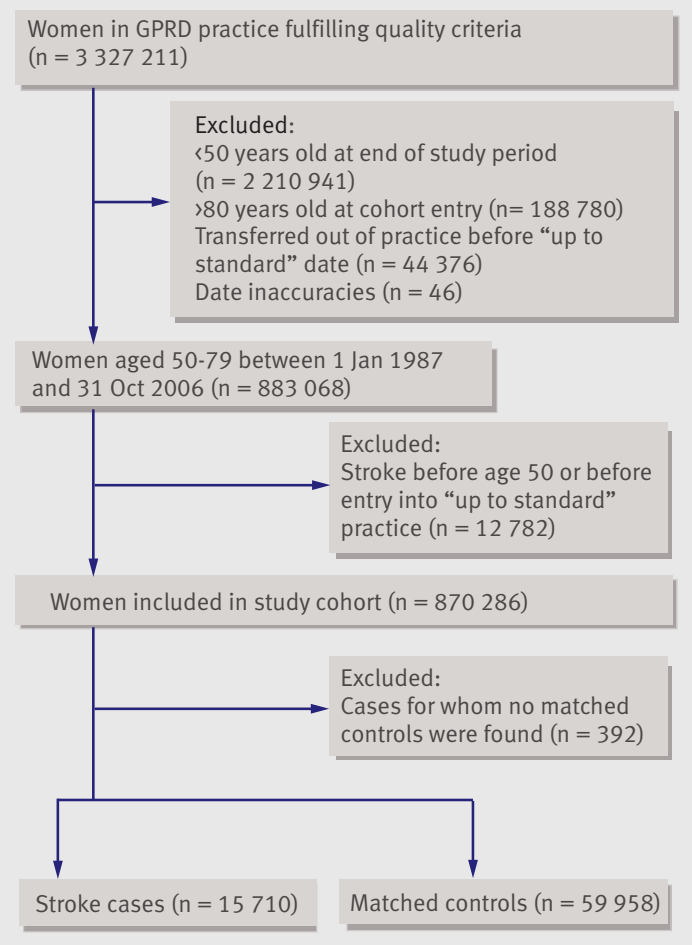

Details of cohort and case-control definitions 
Table 1|Characteristics of women aged $\geq 50$ years who had had a stroke (cases) and their matched controls* (values are percentages (numbers) unless stated otherwise)

\begin{tabular}{|c|c|c|}
\hline Characteristic & Cases $(n=15710)$ & Controls $(n=59958)$ \\
\hline Mean (SD) age (years) & $70.3(7.3)$ & $70.3(7.4)$ \\
\hline $\begin{array}{l}\text { Mean (SD) follow-up from practice's "up } \\
\text { to standard" date (years) } \dagger\end{array}$ & $6.68(4.46)$ & $6.68(4.44)$ \\
\hline \multicolumn{3}{|l|}{ Body weight status: } \\
\hline Obese & $15.5(2434)$ & $13.5(8113)$ \\
\hline Not obese & $54.4(8546)$ & 56.9 (34 143) \\
\hline Unknown & $30.1(4730)$ & $29.5(17702)$ \\
\hline \multicolumn{3}{|l|}{ Smoking status: } \\
\hline Current & $20.8(3264)$ & $13.5(8112)$ \\
\hline Former & $13.0(2043)$ & 11.7 (6995) \\
\hline Never & $42.7(6704)$ & $50.7(30408)$ \\
\hline Unknown & 23.5 (3699) & $24.1(14$ 443) \\
\hline Alcohol misuse & $0.9(142)$ & $0.3(204)$ \\
\hline Hypertension & 45.6 (7159) & 31.4 (18 832) \\
\hline Hyperlipidaemia & $17.7(2783)$ & $11.5(6909)$ \\
\hline Atrial fibrillation & $10.2(1598)$ & $3.5(2072)$ \\
\hline Cardiovascular disease & $23.5(3698)$ & $13.7(8188)$ \\
\hline History of transient ischaemic attack & $15.2(2386)$ & $2.7(1644)$ \\
\hline Diabetes & $10.5(1645)$ & $4.5(2707)$ \\
\hline Hysterectomy & 18.4 (2899) & $18.1(10852)$ \\
\hline Oophorectomy & $4.0(626)$ & $3.8(2253)$ \\
\hline Aspirin use & 27.5 (4317) & $12.6(7542)$ \\
\hline Other non-steroidal anti-inflammatory drug use & $25.5(4002)$ & $23.0(13784)$ \\
\hline
\end{tabular}

the risk of stroke associated with current use of HRT but with oral use as the reference category in order to compare directly the transdermal and oral routes. Our classification of current, past, and non-use of HRT was based on our previous finding that the risk of stroke associated with HRT use is higher at the time of current use and rapidly disappears in the months after discontinuation. ${ }^{12}$

In a separate analysis, we determined the risk of stroke according to the duration of HRT use $(\leq 1$ year or $>1$ year) for women who had been exposed to one HRT type only.

Although the nested case-control approach does not allow a direct estimation of the absolute risk of stroke, we estimated the number of additional strokes according to the route of administration by using the rate of stroke in our study population as the baseline rate and applying the estimated rate ratios for each exposure group.

In addition to the matching factors, all rate ratios were adjusted for body mass index, smoking status, alcohol misuse, and for the presence of diabetes, hyperlipidaemia, hypertension, atrial fibrillation, cardiovascular disease (including angina, coronary heart disease, congestive heart failure, left ventricular hypertrophy, and myocardial infarction), transient ischaemic attack, hysterectomy or oophorectomy at any time before the index date, and aspirin or other non-steroidal anti-inflammatory drug use in the year before the index date. Body mass index was categorised as $<30, \geq 30$, or missing value; smoking was classified as current, former, never, or missing value.

To assess the robustness of our results, we performed sensitivity analyses exploring the effect of potential misclassification of current exposure on the estimated rate ratios. The calculated duration of use was prolonged by 28 days for all cases and controls exposed. Thus some subjects not classified as currently exposed at the index date based on the calculated duration of use in our main analysis became exposed. We also evaluated the impact of missing data for body mass index and smoking status on our results by repeating our analyses using the subgroup of patients with no missing values for any of these variables. All computations were performed using the SAS software version 9.1.3 (SAS Institute, Cary, NC, USA).

\section{RESULTS}

\section{Background data}

We identified a cohort of 883068 women in the General Practice Research Database (GPRD) aged 50-79 between 1 January 1987 and 31 October 2006 who were members of a practice fulfilling quality criteria (figure). Within this cohort, 12782 women had a stroke before the age of 50 , before their registration into the practice, or before the practice achieved "up to standard" status and were therefore excluded, leaving a final cohort of 870286 women. A total of 16102 women in this final cohort had a first diagnosis of stroke during follow-up. Of these, $392(2.4 \%)$ were excluded because no suitable controls could be identified, leaving a study of 15710 cases of stroke and 59958 randomly selected matched controls.

Table 1 describes the characteristics of the cases of stroke and their matched controls (as reported previously ${ }^{12}$ ). The mean age of cases and controls at the index date was 70 years. The mean duration of follow-up in the "up to standard" practices was 6.7 years for cases and controls. As expected, all cardiovascular risk factors were more common in cases than in control subjects.

\section{Use of hormone replacement therapy}

A total of $1214(7.7 \%)$ cases and $4124(6.9 \%)$ controls had received at least one HRT prescription in the year before the index date. Of these, 798 (5.1\%) cases and $2748(4.6 \%)$ controls were current users, with $2.2 \%$ of cases and $1.9 \%$ of controls being current users of oestrogens alone, and $2.4 \%$ of cases and $2.2 \%$ of controls current users of oestrogen-progestogen. In controls, the oral route was more common than the transdermal route, accounting for $72 \%$ of current users of oestrogen-only therapy and $91 \%$ of oestrogen-progestogen therapy. Among these control users, the commonest oestrogen dose was $0.625 \mathrm{mg}$, taken by $46 \%$ of users of oral products, and $50 \mu \mathrm{g}$ taken by $68 \%$ of users of transdermal products. Among the 2025 control users of oral HRT containing oestrogens, $82.7 \%$ had been exposed only to oral preparations at any time before the index date, and, among these, $87.5 \%$ had been 
Table 2 |Crude and adjusted rate ratios of stroke associated with current use of hormone replacement therapy (HRT) by drug type and route of administration (values are percentages (numbers) unless stated otherwise)

\begin{tabular}{|c|c|c|c|c|}
\hline \multirow[b]{2}{*}{ Type of HRT } & \multirow[b]{2}{*}{ Cases $^{*}(n=15710)$} & \multirow[b]{2}{*}{ Controls* $(n=59$ 958) } & \multicolumn{2}{|c|}{ Rate ratio $(95 \% \mathrm{Cl})$} \\
\hline & & & Crude & Adjusted $†$ \\
\hline None & 92.27 (14 496) & $93.12(55834)$ & $1.00 \ddagger$ & $1.00 \ddagger$ \\
\hline Transdermal route: & $0.66(103)$ & $0.74(441)$ & $0.92(0.74$ to 1.14$)$ & $0.95(0.75$ to 1.20$)$ \\
\hline Oestrogen only & $0.52(81)$ & $0.53(317)$ & $1.00(0.78$ to 1.28$)$ & $1.02(0.78$ to 1.34$)$ \\
\hline Oestrogen-progestogen & $0.14(22)$ & $0.21(124)$ & $0.70(0.45$ to 1.11$)$ & $0.76(0.47$ to 1.22$)$ \\
\hline Oral route: & $3.93(618)$ & $3.38(2025)$ & 1.20 (1.09 to 1.33$)$ & $1.28(1.15$ to 1.42$)$ \\
\hline Oestrogen only & $1.67(262)$ & $1.34(802)$ & 1.28 (1.11 to 1.48$)$ & 1.35 (1.16 to 1.58$)$ \\
\hline Oestrogen-progestogen & $2.27(356)$ & 2.04 (1223) & 1.15 (1.02 to 1.31$)$ & $1.24(1.08$ to 1.41$)$ \\
\hline
\end{tabular}

* One case and 7 controls were exposed to tibolone in combination with oestrogen-progestogen, 4 cases and 9 controls were exposed to progestogen only, and 72 cases and 266 controls were exposed to tibolone. These 3 HRT categories were included in the model. Former users of HRT ( 416 cases and 1376 controls) were also included in the model.

†Adjusted for age, body mass index, smoking status, alcohol misuse, diabetes, hyperlipidaemia, hypertension, atrial fibrillation, cardiovascular disease, transient ischaemic attack, aspirin or other NSAID use, and history of hysterectomy or oophorectomy

$\ddagger$ Reference category, defined as no prescription of HRT in the 12 months before index date.

exposed to oral HRT for more than one year. Among the 441 current patch users in the control group, $60.3 \%$ had been exposed only to patches, and most of these for more than one year before the index date (82.3\%). Of note, all these figures do not represent the overall exposure during the entire study period, but instead at the time of the index date for cases and controls.

Since the mean age at the time of stroke for cases (and at the corresponding index date for matched controls) was 70 years, the uptake of HRT was low. In the year before the index date, 2649 transdermal HRT prescriptions were delivered to controls, of which $77 \%$ were oestrogen only, $15 \%$ were transdermal oestrogen-progestogen, and $8 \%$ were oestrogen patch combined with oral progestogen. The duration of $3.3 \%$ of HRT prescriptions could not be calculated, and for these we used the mean duration for the corresponding HRT.

\section{Stroke risk associated with HRT}

The adjusted rate ratio of stroke associated with current use of transdermal oestrogens (alone or with progestogen) was 0.95 (95\% confidence interval 0.75 to 1.20$)$ relative to non-use of HRT (table 2). The rate of stroke did not increase with the addition of a progestogen to the transdermal oestrogens. The rate ratio of stroke for current users of transdermal oestrogens alone was 1.02 (0.78 to 1.34$)$ compared with non-users and $0.76(0.47$ to 1.22 ) for current users of transdermal oestrogens plus progestogen. Conversely, current users of oral oestrogens alone or in combination had a higher rate of stroke compared with non-users of HRT (rate ratio 1.28 (1.15 to 1.42$))$. Current use of oral oestrogens alone increased the risk by $35 \%$ (rate ratio $1.35(1.16$ to 1.58)) and current use of oral oestrogens plus progestogen by $24 \%$ (rate ratio 1.24 (1.08 to 1.41$)$ ).

Direct comparison of transdermal HRT with oral therapy showed that the risk of stroke was lower among transdermal users (rate ratio 0.74 (0.58 to 0.95)). Past use of transdermal HRT did not increase the risk of stroke (rate ratio 0.99 (0.76 to 1.28)) compared with non-use, unlike past use of oral HRT (rate ratio 1.36 (1.17 to 1.59$)$ ). However, this increased risk concerned mainly the first few months after stopping oral HRT: the rate ratio was 1.54 (1.18 to 2.00$)$ for women whose exposure stopped within one month before the index date but was only 1.09 (0.83 to 1.42 ) for women whose exposure stopped more than four months before the index date.

There was a total of 16102 cases of stroke during 5659035 person years of observation, resulting in a rate of 2.85 strokes per 1000 person years. The $28 \%$ increase in risk associated with the use of oral oestrogens (alone or in combination with a progestogen) leads to 0.8 additional strokes per 1000 person years.

Considering the risk of stroke associated with high or low oestrogen doses of transdermal and oral formulations, we found that the risk of stroke was not increased with current use of low dose patches (rate ratio 0.81 (0.62 to 1.05$)$ ) compared with no use, whereas the risk was increased with current use of high doses patches (rate ratio 1.89 (1.15 to 3.11$)$ ) (table 3$)$. The increased risk of stroke associated with current oral use was virtually the same with low dose (rate ratio 1.25 (1.12 to 1.40$)$ ) and high dose (rate ratio 1.48 (1.16 to 1.90$)$ ) compared with no use.

In the group of women currently exposed to one HRT type only, we found that short term users did not have a higher risk of stroke, whether exposed to transdermal oestrogens (rate ratio 0.98 (0.50 to 1.91$)$ ) or to oral oestrogens (rate ratio 1.02 (0.75 to 1.38)) (table 4). Long term users $(>1$ year) of transdermal oestrogens may have had a slightly increased risk (rate ratio 1.13 (0.83 to 1.54$)$ ) whereas long term users of oral oestrogens had a $35 \%$ increased risk (rate ratio 1.35 (1.20 to 1.52$)$ ).

Our sensitivity analyses, which involved the addition of 28 days to the duration of exposure, did not change the sense of our results. The rate of stroke remained virtually the same for current users of transdermal oestrogens alone or in combination (rate ratio $0.95(0.77$ to 1.18$)$ ) and for current users of oral oestrogens alone or in combination, who had an increased rate of stroke (rate ratio 1.30 (1.18 to 1.44$)$ ). Restricting the analyses to patients without missing values for body mass index and smoking status yielded virtually the same results with a rate ratio of 0.99 ( 0.77 to 1.29$)$ 
Table $3 \mid$ Crude and adjusted rate ratios of stroke associated with current use of hormone replacement therapy (HRT) by drug dose and route of administration (values are percentages (numbers) unless stated otherwise)

\begin{tabular}{|c|c|c|c|c|}
\hline \multirow[b]{2}{*}{ Type of HRT } & \multirow[b]{2}{*}{ Cases* $^{*}(n=15710)$} & \multirow[b]{2}{*}{ Controls* $(n=59958)$} & \multicolumn{2}{|c|}{ Rate ratio $(95 \% \mathrm{Cl})$} \\
\hline & & & Crude & Adjusted $†$ \\
\hline None & 92.27 (14 496) & $93.12(55834)$ & $1.00 \ddagger$ & $1.00 \ddagger$ \\
\hline Transdermal route: & $0.66(103)$ & $0.74(441)$ & $0.92(0.74$ to 1.14$)$ & 0.95 (0.75 to 1.20$)$ \\
\hline Low dose $(\leq 50 \mu \mathrm{g})$ & $0.48(76)$ & $0.64(384)$ & $0.78(0.61$ to 1.00$)$ & $0.81(0.62$ to 1.05$)$ \\
\hline High dose $(>50 \mu g)$ & $0.17(27)$ & $0.10(57)$ & 1.87 (1.17 to 2.98$)$ & 1.89 (1.15 to 3.11) \\
\hline Oral route: & $3.93(618)$ & $3.38(2025)$ & $1.20(1.09$ to 1.33$)$ & $1.28(1.15$ to 1.42$)$ \\
\hline Low dose $\S$ & $3.28(515)$ & $2.92(1753)$ & 1.16 (1.04 to 1.29$)$ & $1.25(1.12$ to 1.40$)$ \\
\hline High dose $\S$ & $0.66(103)$ & $0.45(272)$ & 1.51 (1.20 to 1.90$)$ & $1.48(1.16$ to 1.90$)$ \\
\hline
\end{tabular}

*The model also included current users of tibolone, tibolone in combination with oestrogen-progestogen, and progestogen as well as former users of HRT (see table 2 for details).

†Adjusted for age, body mass index, smoking status, alcohol misuse, diabetes, hyperlipidaemia, hypertension, atrial fibrillation, cardiovascular disease, transient ischaemic attack, aspirin or other NSAID use, and history of hysterectomy or oophorectomy.

$\ddagger$ Reference category, defined as no prescription of HRT in the 12 months before index date.

$\S$ Low dose of oral HRT defined by $\leq 0.625 \mathrm{mg}$ of equine oestrogen or $\leq 2 \mathrm{mg}$ of estradiol and high dose of oral HRT defined by $>0.625 \mathrm{mg}$ of equine oestrogen or $>2 \mathrm{mg}$ of estradiol.

for current users of transdermal HRT and 1.26 (1.12 to 1.42) for current users of oral HRT.

\section{DISCUSSION}

Our population based, observational study of the risk of stroke associated with oral and transdermal hormone replacement therapy in postmenopausal women showed that the risk differed according to the route of administration of HRT and oestrogen dose. Indeed, we found that use of low dose transdermal oestrogen replacement therapy with or without progestogen was not associated with an increased risk of stroke, although a slightly increased risk with long term use cannot be excluded. Conversely, high dose transdermal HRT and oral HRT increased the risk of stroke by $25 \%-88 \%$.

\section{Comparison with other studies}

To our knowledge, the influence of route of administration of HRT on the risk of stroke has not been studied to date. A recent cohort study using the General Practice Research Database (GPRD) reported a lower risk of transient ischaemic attack with transdermal oestrogens (odds ratio 0.86 (95\% confidence interval 0.43 to 1.73 ) than with oral oestrogen (odds ratio 1.47 (1.09 to 1.97$)) .{ }^{4}$ The number of transdermal oestrogen users was small as reflected by the wide confidence interval and the risk of stroke could not be estimated.

Our finding of an increased rate of stroke associated with current use of oral oestrogens is in accordance with results of most randomised controlled trials and recent meta-analyses. ${ }^{1-314-20}$ Our results suggest that this risk is higher in prolonged users of oral HRT, although the large confidence intervals preclude any firm conclusion and an increased risk in recent users cannot be excluded. In a recent study also using the GPRD, the risk of transient ischaemic attack and ischaemic stroke was more marked during the first year of HRT therapy. ${ }^{4}$ However, no distinction was made between new users and individuals who had switched from another HRT type, whereas we considered only new users who had not been exposed to other HRT types or formulations.

Although clinical studies are lacking, there is biological evidence to support the idea that risk of vascular events differs according to the route of administration of HRT. ${ }^{21}$ The transdermal route avoids the first pass effect in the liver and therefore reduces the induction of hepatic protein synthesis of clotting factors and various inflammation markers. In light of our results of an increased risk of stroke with transdermal products containing high doses of oestrogens, however, the biological impact of the route of administration may vary according to the oestrogen dose delivered. Many studies found that transdermal HRT administration has no or minimal effect on several cardiovascular and thromboembolic risk markers, unlike oral oestrogens. However, the impact of different doses of oestrogen was not considered, as the $50 \mu \mathrm{g}$ dose was almost exclusively studied. ${ }^{7}$

Information on risk of ischaemic heart disease associated with different routes of administration of oestrogens is scarce. The few observational studies found no increased risk of myocardial infarction with transdermal oestrogens, though the same studies did not find an increased risk with the oral form either. ${ }^{22}{ }^{23}$ One randomised, placebo controlled trial, the Papworth HRT Atherosclerosis Study (PHASE), examined the risk of acute coronary events (cardiac mortality, non-fatal myocardial infarction, and hospitalisation with unstable angina) associated with transdermal oestrogens (dose $80 \mu \mathrm{g}$ ) in postmenopausal women with angiographically proved ischaemic heart disease. ${ }^{24}$ Among the 255 women recruited, 134 were randomly assigned to transdermal oestrogen (alone or combined with a progestogen) and 121 to placebo. The HRT group had a higher event rate compared with the placebo group, but the difference was not statistically significant (rate ratio 1.29 (95\% confidence interval 0.84 to 1.95$)$ ). However, the study had several limitations, including a high withdrawal rate in the HRT group $(40 \%)$. 
Table $4 \mid$ Crude and adjusted rate ratios of stroke associated with current use of oestrogen (alone or in combination) by duration of use and route of administration in women not previously exposed to other hormone replacement therapy (HRT)* (values are percentages (numbers) unless stated otherwise)

\begin{tabular}{|c|c|c|c|c|}
\hline \multirow[b]{2}{*}{ Type of HRT } & \multirow[b]{2}{*}{ Cases* $^{*}(n=15710)$} & \multirow[b]{2}{*}{ Controls* $(n=59958)$} & \multicolumn{2}{|c|}{ Rate ratio $(95 \% \mathrm{Cl})$} \\
\hline & & & Crude & Adjusted $†$ \\
\hline None & 92.27 (14 496) & $93.12(55834)$ & $1.00 \ddagger$ & $1.00 \ddagger$ \\
\hline Exclusive transdermal route: & $0.46(72)$ & $0.44(266)$ & $1.05(0.80$ to 1.36$)$ & 1.10 (0.83 to 1.46$)$ \\
\hline For $\leq 1$ year & $0.08(12)$ & $0.08(47)$ & $0.95(0.50$ to 1.80$)$ & $0.98(0.50$ to 1.91$)$ \\
\hline For $>1$ year & $0.38(60)$ & 0.37 (219) & 1.07 (0.80 to 1.43$)$ & $1.13(0.83$ to 1.54$)$ \\
\hline Exclusive oral route: & $3.28(516)$ & $2.79(1675)$ & 1.21 (1.09 to 1.34$)$ & $1.30(1.16$ to 1.45$)$ \\
\hline For $\leq 1$ year & $0.38(59)$ & $0.38(230)$ & 0.92 (0.69 to 1.23$)$ & $1.02(0.75$ to 1.38$)$ \\
\hline For $>1$ year & $2.91(457)$ & $2.41(1445)$ & $1.26(1.13$ to 1.41$)$ & $1.35(1.20$ to 1.52$)$ \\
\hline
\end{tabular}

*The model also included current users of tibolone, tibolone in combination with oestrogen-progestogen, and progestogen; former users of HRT; as well as current oestrogen users (alone or in combination) who switched from another formulation or HRT product.

†Adjusted for age, body mass index, smoking status, alcohol misuse, diabetes, hyperlipidaemia, hypertension, atrial fibrillation, cardiovascular disease, transient ischaemic attack, aspirin or other NSAID use, and history of hysterectomy or oophorectomy.

$\ddagger$ Reference category, defined as no prescription of HRT in the 12 months before index date.

More information is available on the impact of the route of oestrogen administration on the risk of venous thromboembolism. Although there are no randomised controlled trials, recent observational studies and one meta-analysis suggest that transdermal oestrogen does not increase the risk of venous thrombosis in postmenopausal women, ${ }^{25-27}$ and that it confers no additional risk of venous thromboembolism in obese women ${ }^{28}$ or in those with prothrombotic mutations, in contrast to oral oestrogens..$^{29}$ The risk of venous thrombosis associated with different doses of transdermal oestrogens was not investigated. Two other studies found no difference between transdermal and oral use, but their results were based on only five and seven cases using transdermal oestrogens, respectively. ${ }^{3031}$

\section{Strengths and limitations of the study}

The use of a computerised longitudinal database provides several advantages in terms of selection of subjects and measurement of exposure. Selection bias is unlikely since we analysed a well defined cohort of all women aged 50-79 registered in the GPRD during the study period using a nested case-control design. Classification of exposure to HRT was made according to the prescriptions issued by the women's physicians, which are electronically recorded at the time of prescription, precluding any information (recall) bias due to the retrospective assessment of exposure. Some degree of misclassification could have occurred since exposure status was not based on prescriptions actually filled or taken by the patients, and information on compliance was not available. However, examining potential misclassification of exposure in sensitivity analyses did not change our findings.

We were able to adjust for many potential confounder variables, including some lifestyle risk factors. One unmeasured potential confounder was age at menopause. Although we cannot exclude the presence of some residual confounding, this confounding is likely to be non-differential between the two routes of HRT administration. In other words, if patients with a higher cardiovascular risk profile were more likely to be prescribed HRT before the results of clinical trials showing no cardiovascular benefit, it is unlikely that one route of administration would be favoured over the other. Also, we could not adjust for our cohort subjects' socioeconomic status or educational attainment, but our matching of cases and controls on the general practice attended represents an indirect attempt to adjust for such potential confounders. We cannot, however, exclude the possibility that users of transdermal and oral HRT differed for such characteristics, resulting in some residual confounding. Finally, the changes in trends of HRT exposure over time, which were likely to have occurred, were taken into account in our analyses by the matching of cases and controls for calendar time.

Some potential limitations inherent to the database must be considered. We did not have access to patients' charts to validate the diagnosis of stroke. However, the use of GPRD diagnosis codes for stroke has been shown to be accurate in a recent study where 78 of the $88(89 \%)$ recorded stroke diagnosis codes were in agreement with the written medical records. ${ }^{32}$ We were unable to differentiate between ischaemic and haemorrhagic stroke accurately, as most diagnostic codes for stroke do not include this information. We therefore could not explore the effect of the route of administration on stroke subtypes. Some delay may also exist between the date of occurrence of stroke and its recording in the GPRD, although this should have minor impact on our results as we did not study the acute effect of HRT. Finally the exposure to HRT at the time of stroke was low, around 7\% in both cases and controls. This is not surprising, however, considering that this percentage reflects the current exposure of patients at the time of stroke, and not the overall percentage of patients exposed at any time during followup. Also, because of the small number of exposed cases, we did not estimate the impact of the type of combined progestogen.

\section{Conclusions}

The increased risk of stroke associated with HRT use has been a constant finding among most observational studies and randomised controlled trials to date. Our study suggests that the use of transdermal oestrogen 


\section{WHAT IS ALREADY KNOWN ON THIS TOPIC}

Oestrogen replacement therapy with or without progestogen is associated with an increased risk of stroke in postmenopausal women

\section{WHAT THIS STUDY ADDS}

The use of transdermal hormone replacement therapy containing low doses of oestrogen was not associated with an increased risk of stroke, in contrast to the oral route of oestrogen alone or combined with a progestogen

Transdermal administration of hormone replacement therapy may be a safer alternative to the oral route of administration
9 Garcia Rodriguez LA, Perez GS. Use of the UK General Practice Research Database for pharmacoepidemiology. Br J Clin Pharmacol 1998;45:419-25.

10 Jick H, Jick SS, Derby LE. Validation of information recorded on general practitioner based computerised data resource in the United Kingdom. BMJ 1991;302:766-8.

11 Jick SS, Kaye JA, Vasilakis-Scaramozza C, Garcia Rodriguez LA, Ruigomez A, Meier CR, et al. Validity of the general practice research database. Pharmacotherapy 2003;23:686-9.

12 Renoux C, Dell'Aniello S, Garbe E, Suissa S. Hormone replacement therapy use and the risk of stroke. Maturitas 2008;61:305-9.

13 Andersohn F, Schade R, Suissa S, Garbe E. Cyclooxygenase-2 selective nonsteroidal anti-inflammatory drugs and the risk of ischemic stroke: a nested case-control study. Stroke 2006;37:1725-30.

14 Simon JA, Hsia J, Cauley JA, Richards C, Harris F, Fong J, et al. Postmenopausal hormone therapy and risk of stroke: The Heart and Estrogen-progestin Replacement Study (HERS). Circulation 2001;103:638-42.

replacement therapy containing low doses of oestrogen could be associated with a lower risk of stroke than the oral route of administration since we found no significant difference in stroke rates for low dose transdermal users compared with non-users. Although these results alone do not represent definitive evidence to promote the use of the transdermal route over oral administration of oestrogen replacement therapy, this study should encourage further research on the importance of the route of administration to define the role of transdermal oestrogens in the therapeutic arsenal for the treatment of menopausal symptoms.

Contributors: All authors contributed to the study design, SD'A performed the statistical analysis, CR wrote the initial draft, and all authors critically revised the manuscript. All authors had full access to all of the data (including statistical reports and tables) in the study and can take responsibility for the integrity of the data and the accuracy of the data analysis. SS is the guarantor for the paper.

Funding: This research was funded by grants from the Canadian Institutes of Health Research (CIHR), the Canadian Foundation for Innovation, and Organon. SS is the recipient of a distinguished investigator award from the CIHR. CR is the recipient of a postdoctoral fellowship from the Multiple Sclerosis Society of Canada

The study sponsor had no role in study design; in the collection, analysis, and interpretation of data; in the writing of the report; or in the decision to submit the article for publication. All authors declare they are independent from all source of funding.

Competing interests: SS received research funding from Organon, Schering, and Wyeth, makers of hormone replacement therapy. EG received research funding and acted as a consultant to Schering AG Ethical approval: The study was approved by the Scientific and Ethical Advisory Board of the GPRD.

Data sharing: No additional data available.

1 Bath PM, Gray LJ. Association between hormone replacement therapy and subsequent stroke: a meta-analysis. $B M$ J 2005;330:342.

2 Magliano DJ, Rogers SL, Abramson MJ, Tonkin AM. Hormone therapy and cardiovascular disease: a systematic review and meta-analysis. BJOG 2006;113:5-14.

3 Sare GM, Gray LJ, Bath PM. Association between hormone replacement therapy and subsequent arterial and venous vascular events: a meta-analysis. Eur Heart / 2008;29:2031-41.

4 Arana A, Varas C, Gonzalez-Perez A, Gutierrez L, Bjerrum L, Garcia Rodriguez LA. Hormone therapy and cerebrovascular events: a population-based nested case-control study. Menopause 2006;13:730-6.

5 Archer DF. Percutaneous 17 beta-estradiol gel for the treatment of vasomotor symptoms in postmenopausal women. Menopause 2003;10:516-21.

6 Place VA, Powers M, Darley PE, Schenkel L, Good WR. A double-blind comparative study of Estraderm and Premarin in the amelioration of postmenopausal symptoms. Am I Obstet Gynecol 1985;152:1092-9.

7 Hemelaar M, van der Mooren MJ, Rad M, Kluft C, Kenemans P. Effects of non-oral postmenopausal hormone therapy on markers of cardiovascular risk: a systematic review. Fertil Steril 2008;90:642-72.

8 Walley T, Mantgani A. The UK General Practice Research Database. Lancet 1997;350:1097-9.
15 Viscoli CM, Brass LM, Kernan WN, Sarrel PM, Suissa S, Horwitz RI. A clinical trial of estrogen-replacement therapy after ischemic stroke. $N$ Engl/ Med 2001:345:1243-9.

16 Cherry N, Gilmour K, Hannaford P, Heagerty A, Khan MA, Kitchener H, et al. Oestrogen therapy for prevention of reinfarction in Lancet 2002;360:2001-8.

17 Wassertheil-Smoller S, Hendrix SL, Limacher M, Heiss G, Kooperberg C, Baird A, et al. Effect of estrogen plus progestin on stroke in postmenopausal women: the Women's Health Initiative: randomized trial. JAMA 2003;289:2673-84.

18 Anderson GL, Limacher M, Assaf AR, Bassford T, Beresford SA, Black $\mathrm{H}$, et al. Effects of conjugated equine estrogen in postmenopausal women with hysterectomy: the Women's Health Initiative randomized controlled trial. JAMA 2004;291:1701-12.

19 Hendrix SL, Wassertheil-Smoller S, Johnson KC, Howard BV, Kooperberg C, Rossouw JE, et al. Effects of conjugated equine estrogen on stroke in the Women's Health Initiative. Circulation 2006;113:2425-34

20 Rossouw JE, Prentice RL, Manson JE, Wu L, Barad D, Barnabei VM, et al. Postmenopausal hormone therapy and risk of cardiovascular disease by age and years since menopause. JAMA 2007; 297:1465-77.

21 Modena MG, Sismondi P, Mueck AO, Kuttenn F, Lignieres B, Verhaeghe J, et al. New evidence regarding hormone replacement therapies is urgently required: transdermal postmenopausal hormone therapy differs from oral hormone therapy in risks and benefits. Maturitas 2005;52:1-10.

22 Varas-Lorenzo C, Garcia-Rodriguez LA, Perez-Gutthann S, Duque-Oliart A. Hormone replacement therapy and incidence of acute myocardial infarction. A population-based nested case-control study. Circulation 2000;101:2572-8.

23 de Vries CS, Bromley SE, Farmer RD. Myocardial infarction risk and hormone replacement: differences between products. Maturitas 2006;53:343-50.

24 Clarke SC, Kelleher J, Lloyd-Jones H, Slack M, Schofiel PM. A study of hormone replacement therapy in postmenopausal women with ischaemic heart disease: the Papworth HRT atherosclerosis study. BJOG 2002;109:1056-62.

25 Scarabin PY, Oger E, Plu-Bureau G. Differential association of oral and transdermal oestrogen-replacement therapy with venous thromboembolism risk. Lancet 2003;362:428-32.

26 Canonico M, Oger E, Plu-Bureau G, Conard J, Meyer G, Levesque H, et al. Hormone therapy and venous thromboembolism among postmenopausal women: impact of the route of estrogen administration and progestogens: the ESTHER study. Circulation 2007;115:840-5.

27 Canonico M, Plu-Bureau G, Lowe GD, Scarabin PY. Hormone replacement therapy and risk of venous thromboembolism in postmenopausal women: systematic review and meta-analysis. BMJ 2008;336:1227-31

28 Canonico M, Oger E, Conard J, Meyer G, Levesque H, Trillot N, et al. Obesity and risk of venous thromboembolism among postmenopausal women: differential impact of hormone therapy by route of estrogen administration. The ESTHER Study. / Thromb Haemost 2006;4:1259-65.

29 Straczek C, Oger E, Yon de Jonage-Canonico MB, Plu-Bureau G, Conard J, Meyer G, et al. Prothrombotic mutations, hormone therapy, and venous thromboembolism among postmenopausal women: impact of the route of estrogen administration. Circulation 2005;112:3495-500.

30 Daly E, Vessey MP, Hawkins MM, Carson JL, Gough P, Marsh S. Risk of venous thromboembolism in users of hormone replacement therapy. Lancet 1996:348:977-80.

31 Perez GS, Garcia Rodriguez LA, Castellsague J, Duque OA. Hormone replacement therapy and risk of venous thromboembolism: population based case-control study. BMJ 1997;314:796-800.

32 Hall GC, Brown MM, Mo J, MacRae KD. Triptans in migraine: the risks of stroke, cardiovascular disease, and death in practice. Neurology 2004;62:563-8.

Accepted: 8 November 2009 postmenopausal women: a randomised placebo controlled trial. 